\title{
EGR3 Immediate Early Gene and the Brain-Derived Neurotrophic Factor in Bipolar Disorder
}

\author{
Bianca Pfaffenseller ${ }^{1 *}$, Flavio Kapczinski ${ }^{2 *}$, Amelia L. Gallitano ${ }^{3}$ and Fábio Klamt ${ }^{4}$ \\ 'Laboratory of Molecular Psychiatry, Hospital de Clínicas de Porto Alegre, Universidade Federal do Rio Grande do Sul, \\ Porto Alegre, Brazil, 'Department of Psychiatry and Behavioral Neurosciences, McMaster University, Hamilton, ON, Canada, \\ ${ }^{3}$ Department of Basic Medical Sciences, College of Medicine, University of Arizona, Phoenix, AZ, United States, ${ }^{4}$ Laboratory \\ of Cellular Biochemistry, Department of Biochemistry, Universidade Federal do Rio Grande do Sul, Porto Alegre, Brazil
}

OPEN ACCESS

Edited by:

Catherine Belzung,

François Rabelais University, France

Reviewed by:

Jean-Philippe Guilloux, Université Paris-Sud, France

Anthony Carrard, Centre Hospitalier Universitaire Vaudois (CHUV), Switzerland

*Correspondence: Bianca Pfaffenseller bianca.pfaffenseller@gmail.com

Flavio Kapczinski flavio.kapczinski@gmail.com

Received: 21 June 2017 Accepted: 17 January 2018 Published: 05 February 2018

Citation:

Pfaffenseller B, Kapczinski F, Gallitano AL and Klamt F (2018) EGR3 Immediate Early Gene and the Brain-Derived Neurotrophic

Factor in Bipolar Disorder.

Front. Behav. Neurosci. 12:15. doi: 10.3389/fnbeh.2018.00015
Bipolar disorder (BD) is a severe psychiatric illness with a consistent genetic influence, involving complex interactions between numerous genes and environmental factors. Immediate early genes (IEGs) are activated in the brain in response to environmental stimuli, such as stress. The potential to translate environmental stimuli into long-term changes in brain has led to increased interest in a potential role for these genes influencing risk for psychiatric disorders. Our recent finding using network-based approach has shown that the regulatory unit of early growth response gene 3 (EGR3) of IEGs family was robustly repressed in postmortem prefrontal cortex of BD patients. As a central transcription factor, EGR3 regulates an array of target genes that mediate critical neurobiological processes such as synaptic plasticity, memory and cognition. Considering that EGR3 expression is induced by brain-derived neurotrophic factor (BDNF) that has been consistently related to BD pathophysiology, we suggest a link between BDNF and EGR3 and their potential role in BD. A growing body of data from our group and others has shown that peripheral BDNF levels are reduced during mood episodes and also with illness progression. In this same vein, BDNF has been proposed as an important growth factor in the impaired cellular resilience related to BD. Taken together with the fact that EGR3 regulates the expression of the neurotrophin receptor p75NTR and may also indirectly induce BDNF expression, here we propose a feed-forward gene regulatory network involving EGR3 and BDNF and its potential role in $\mathrm{BD}$.

Keywords: immediate early genes, early growth response gene 3 (EGR3), brain-derived neurotrophic factor (BDNF), bipolar disorder, neuroplasticity, regulatory network

Bipolar disorder (BD) is a chronic and potentially severe and disabling mental illness that affects between $1 \%$ and $3 \%$ of the population worldwide (Merikangas et al., 2011), and is characterized by episodes of mania and depression. Studies evaluating concordance rates between monozygotic twins indicate that $40 \%-70 \%$ of risk for BD is genetically determined (Kieseppa et al., 2004; Craddock and Sklar, 2013). BD is likely influenced by numerous genes, which may individually contribute only a small risk for the disorder but may interact at the gene-network level and respond to environmental stimuli in a complex interaction.

In addition to the genetic contribution to BD, environment influences (Schmitt et al., 2014; Aldinger and Schulze, 2017) risk through both stressors and protective factors, such as childhood 
trauma and level of maternal care (Champagne and Curley, 2009; Jansen et al., 2016; Aldinger and Schulze, 2017). The impact that environmental has on the clinical $\mathrm{BD}$ course (Aldinger and Schulze, 2017) suggests a potential role for genes that are involved in the response and adaptation to stress. This capacity of immediate early genes (IEGs) to translate environmental stimuli into long-term alterations in the brain makes this class of genes of great interest to the field of psychiatry.

\section{IMMEDIATE EARLY GENES AND PSYCHIATRY}

IEGs are a class of genes rapidly and transiently activated in response to a wide range of environmental stimuli (Senba and Ueyama, 1997). Many IEGs encode transcription factors, which regulate downstream target genes that presumably mediate their roles in neurobiological processes including synaptic plasticity and memory formation (Gallitano-Mendel et al., 2007; Poirier et al., 2008; Pérez-Cadahía et al., 2011). Early growth response (EGR) proteins are a family of IEG-encoded transcription factors: EGR1, EGR2, EGR3 and EGR4 (Beckmann and Wilce, 1997; Pérez-Cadahía et al., 2011). EGRs could translate environmental influence into long-term changes in the brain and thus contribute to neuronal plasticity, which has driven to the hypothesis that dysfunction in EGRs may be implicated in both the genetic and environmental involvement on psychiatric disorders susceptibility (Moises et al., 2002; Hanson and Gottesman, 2005; Gallitano et al., 2012; Huentelman et al., 2015).

Studies investigating the potential role of EGR family genes on risk for psychiatric disorders have focused most on the schizophrenia; the most positive findings have been on early growth response gene 3 (EGR3). Single nucleotide polymorphisms (SNPs) in EGR3 are associated with schizophrenia (Kim S. H. et al., 2010; Zhang et al., 2012; Huentelman et al., 2015), and EGR3 mRNA expression is decreased in the postmortem brains of schizophrenia patients compared with controls (Mexal et al., 2005; Yamada et al., 2007). Furthermore, a bioinformatics analysis of the network of transcription factors and microRNAs associated with schizophrenia indicated $E G R 3$ as a central gene in this regulatory network (Guo et al., 2010).

Regarding a potential role for EGRs in BD, a study focused on association of genes related to circadian rhythms with $\mathrm{BD}$ found a nominally significant association for EGR3 (Mansour et al., 2009). A family-based association study, although limited by small sample size, also showed a nominal and preliminary association of EGR3 with risk for BD in children (Gallitano et al., 2012), suggesting this gene as a target for subsequent larger follow-up evaluation. Our recent study using a networkbased approach showed that the regulatory unit of EGR3 was robustly reduced in both of the two independent bipolar gene expression signatures examined from postmortem prefrontal cortex (Pfaffenseller et al., 2016), suggesting the entire network centered on EGR3 might be dysregulated in $\mathrm{BD}$.

Interestingly, EGR3-deficient mice, knockout animals generated by targeted mutagenesis in embryonic stem cells (Tourtellotte and Milbrandt, 1998) and thus lacking functional EGR3 in all cells throughout development, show both physiologic and behavioral changes that corroborate with models in psychiatry. Such alterations involve a heightened stress-reactivity (indicated by both an increased behavioral response and elevated corticosterone release following handling, a mild stressor test), hyperactivity in the locomotor activity test (indicating a psychosis-like phenotype), disrupted habituation to environmental stimuli and social cues and increased aggressive behavior toward an unfamiliar animal (Gallitano-Mendel et al., 2007, 2008). These observations suggest that EGR3 may be involved in biological mechanisms needed to an appropriate response to stress that possibly are dysfunctional in $\mathrm{BD}$. Psychosis-like phenotypes and hyperactivity observed in these EGR3-deficient mice could be reversed with antipsychotic drugs used in treatment of psychiatric disorders, providing an additional support for these findings (Gallitano-Mendel et al., 2008; Williams et al., 2012).

In this scenario, a recent study showed that EGR3 seems to play an essential role in the susceptibility to stress since it was related to dendritic atrophy in nucleus accumbens medium spiny neurons in mice susceptible to the social defeat stress model, and EGR3 knockdown inhibited this dendritic atrophy (Francis et al., 2017). The authors suggest that these alterations in dendritic structure mediated by EGR3 could be responsible for loss in the total number of synapses and consequently reduction in the excitatory transmission observed in these defeated mice. This molecular mechanism mediated by EGR3 could reinforce its role in regulating homeostasis and cellular adaptations possibly underlying stress-induced behavior, which highlight the relevance in studying this transcription factor in psychiatry.

\section{EARLY GROWTH RESPONSE 3 PATHWAY}

EGR genes are expressed at basal levels throughout the brain, such as the cortex, the hippocampus and the basal ganglia as observed in animal studies (Senba and Ueyama, 1997). EGR3 expression is rapidly induced at high levels in response to environmental alterations, including stressful stimuli and sleep deprivation (Honkaniemi et al., 2000; Thompson et al., 2010; Maple et al., 2015).

The EGR3 expression in neurons is regulated by synaptic activity and is mediated by MAPK-ERK signaling (O'Donovan et al., 1999; Li et al., 2007). Studies have improved the understanding about the signaling cascade that leads to EGR3 expression. EGR3 is induced downstream of numerous proteins, comprising neuregulin 1 (NRG1), calcineurin $(\mathrm{CaN})$, $\mathrm{N}$-methyl-D-aspartate (NMDA) receptors and neurotrophins such as brain-derived neurotrophic factor (BDNF) and nerve growth factor (NGF; Yamagata et al., 1994; Hippenmeyer et al., 2002; Roberts et al., 2006; Yamada et al., 2007; Eldredge et al., 2008).

As a transcription factor, EGR3 could, in turn, activate numerous downstream targets that participate in processes such as synaptic plasticity, axon and dendrites extension and modulation of receptors. Experimental studies have identified effects of EGR3 on NMDA receptors (NMDAR; GallitanoMendel et al., 2007), type A gamma amino butyric acid 
(GABA) receptors (Roberts et al., 2006), and NGF receptors ( $p 75 N T R$, Gao et al., 2007). EGR3 also regulates Arc (activity regulated cytoskeletal associated gene; Li et al., 2005), which modifies synapses in response to environmental stimuli, and genes involved in the development and branching of axons and dendrites (Quach et al., 2013). Moreover, it may modulate genes involved in microglia dysregulation such as triggering receptor expressed on myeloid cells 1 (TREM-1, Weigelt et al., 2011). Thus, requirement for EGR3 in processes of memory, learning and neuroplasticity (Gallitano-Mendel et al., 2007; Li et al., 2007) is presumably to be determined by these and possibly other EGR3 target genes not yet identified (Figure 1).

\section{BRAIN-DERIVED NEUROTROPHIC FACTOR AND BIPOLAR DISORDER}

BDNF is the most highly expressed neurotrophin in the CNS, including brain regions associated with emotion modulation and cognitive processing such as prefrontal cortex, amygdala and hippocampus (Lu et al., 2005, 2014). In addition to its expression in the brain, BDNF is also expressed in peripheral tissues (Fujimura et al., 2002). BDNF plays a critical role in neuronal survival and differentiation, dendritic arborization, synaptic plasticity and also in complex process such as memory consolidation and learning (Minichiello, 2009; Park and Poo, 2013; Lu et al., 2014). BNDF is one of the most extensively investigated biomarkers in BD (Post, 2007; Grande et al., 2010).

Some studies have associated changes in peripheral BDNF levels with BD state, suggesting that serum BDNF levels may represent a potential biomarker of mood episodes. A study by Cunha et al. (2006) reported that patients experiencing an episode of either mania, hypomania, or depression had reduced serum BDNF levels compared to euthymic patients, who had BDNF levels similar to healthy subjects. Another study also showed decreased BDNF levels in transformed lymphoblasts from BD patients in comparison to controls (Tseng et al., 2008). Subsequently, meta-analyses have supported that patients in either a depressive or a manic state have lower blood levels of BDNF than healthy individuals; and serum BDNF levels in euthymic patients did not differ from those observed in controls (Lin, 2009; Fernandes et al., 2011, 2014). A more recent meta-analysis indicated that peripheral BDNF levels are reduced in patients compared to healthy controls, regardless of mood state (Munkholm et al., 2015). Considering central tissue,

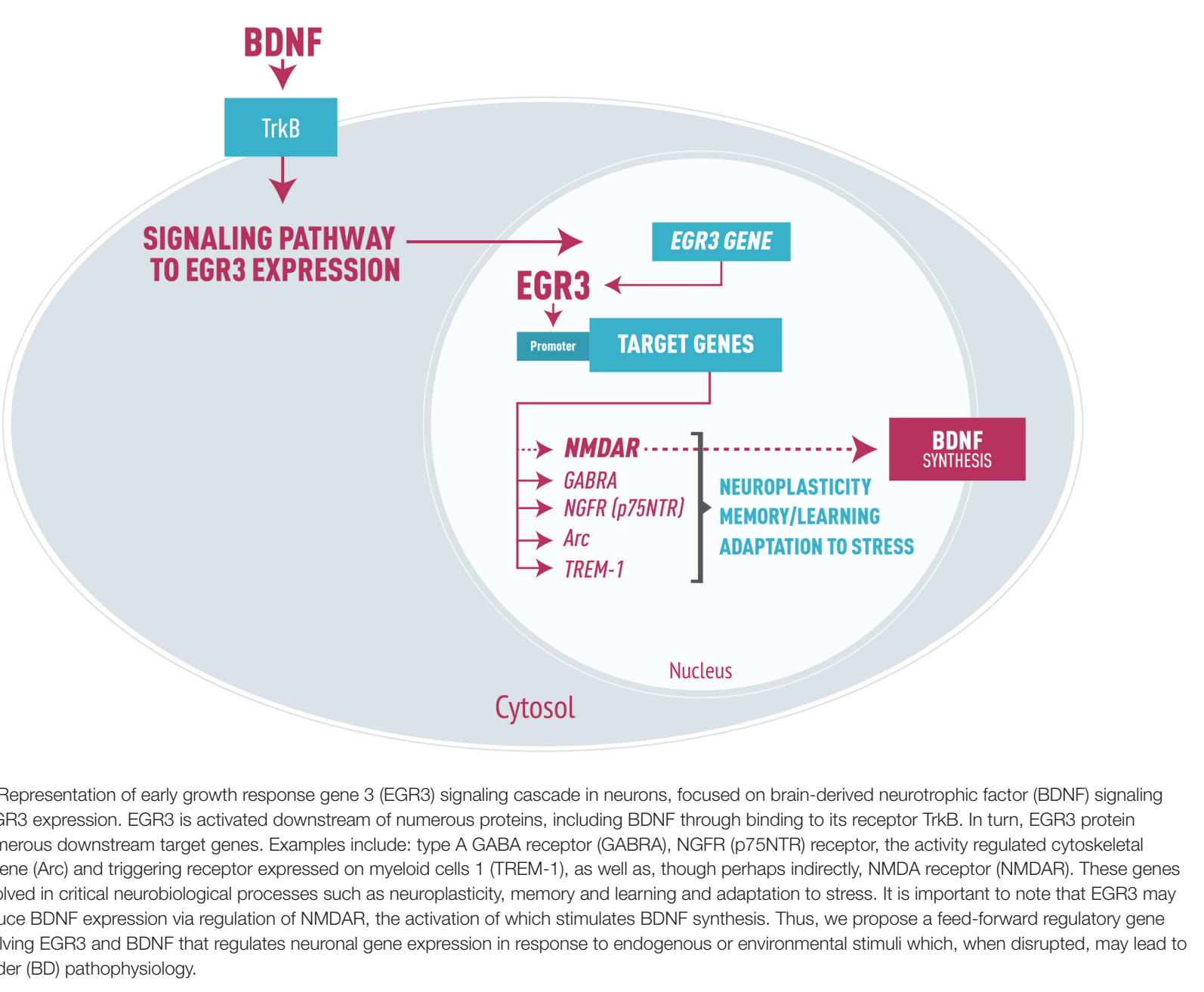


postmortem studies also have importantly reported alterations in $\mathrm{BDNF}$ in BD. For instance, a meta-analysis using postmortem findings from the Stanley Neuropathology Consortium found lower hippocampus BDNF protein levels in BD (Knable et al., 2004). Consistent with this analysis, recent studies have shown that BDNF mRNA was significantly reduced in the hippocampus of $\mathrm{BD}$ patients compared to healthy subjects (Thompson Ray et al., 2011; Reinhart et al., 2015). Decreased levels of BDNF have been also found in frontal cortex (protein and mRNA; Kim H. W. et al., 2010) and in inferior and superior temporal gyrus (mRNA) of BD patients (Ray et al., 2014).

Other studies suggest that BDNF may be associated with illness progression. One report showed that BD patients in later stages of the illness show decreased BDNF levels compared to patients in earlier stages, even during euthymic periods (Kauer-Sant'Anna et al., 2009). Moreover, serum BDNF levels are inversely associated with both duration of illness (KauerSant'Anna et al., 2009) and with severity of manic and depressive symptoms (Cunha et al., 2006). Overall the majority of studies indicated that levels of this neurotrophic factor are reduced in bipolar patients compared to controls.

Several studies have been performed to elucidate the mechanisms involved in the presumed reduction in BDNF levels in BD. Some of them have studied polymorphisms in the $B D N F$ gene such as the polymorphism involving a methionine substitution for a valine at codon 66 (val66met) in the promoter region of the gene. However, the findings regarding association between the val66met polymorphism and BD are divergent (Sklar et al., 2002; Neves-Pereira et al., 2005), which suggests that this particular variant does not explain the altered BNDF levels in BD (Post, 2007).

The apparent decrease in BDNF levels seen in patients would be expected to result in disruption of the intracellular signaling cascades that are normally regulated by BDNF, such as PLC/PKC, $\mathrm{PI} 3 \mathrm{~K} / \mathrm{Akt}$ and Ras/Erk pathways, interfering with processes regulated by this neurotrophin, such as neuronal differentiation and survival, and synaptic plasticity. In fact, BD has been associated with changes in factors involved in neuroplasticity and resilience pathways, including alterations in apoptotic factors, synaptic markers, neurotrophic and inflammatory factors and oxidative stress markers, as well as in processes related to circadian rhythm, neuronal development and calcium metabolism (Kim H. W. et al., 2010; Frey et al., 2013).

Neuropathological findings in the postmortem brains of $\mathrm{BD}$ patients demonstrate the types of abnormalities in neuroplasticity one would expect to see from a deficit in neurotrophic factors. For example, morphometric studies show that patients have enlarged third and lateral ventricles, decreased volume of the orbital and medial prefrontal cortices, ventral striatum and mesotemporal cortex and increased volume of the amygdala compared to controls (Strakowski et al., 2005). Interestingly, such neuroanatomical changes have been found to be more pronounced in patients with multiple mood episodes (Strakowski et al., 2002), suggesting that these abnormalities may increase with severity of the illness (Fornito et al., 2007; Berk et al., 2011). An effective neuroplasticity, considered a cellular and molecular level of adaptation, is likely necessary for the process of resilience, which involves a wholeorganism level response to events. Thus, the abnormalities in neuroplasticity possibly translate into reduced resilience related to recurrent mood episodes and illness progression, which could reflect clinically in cognitive impairments in $\mathrm{BD}$ patients. In fact, meta-analyses show that most patients exhibit neurocognitive dysfunction, and the most impaired domains are attention, verbal learning, memory and executive functions (Robinson et al., 2006; Bourne et al., 2013; Bortolato et al., 2015).

These findings support the "allostatic load" hypothesis that we have previously described (Kapczinski et al., 2008). This hypothesis asserts that the clinical BD course is determined by a combination of the individual's genetic makeup, history of stressful life events and degree and duration of episodes of mental illness. These factors are connected in a feedback loop that worsens the patient's degree of symptoms or overall life function, leading to a progressive illness course associated with biological and brain changes, and cognitive and functioning impairment-hypothesis of BD neuroprogression (Berk, 2009; Fries et al., 2012). Since stress plays an essential role in both the onset and progression of $\mathrm{BD}$, it is noteworthy that BDNF-related neuroplasticity may be a crucial mediator of the effects of stress on BD. Thus, we could assume that a possible dysfunction in neurotrophin pathway might influence an increased vulnerability of $\mathrm{BD}$ patients to stressful conditions.

\section{LINK BETWEEN EARLY GROWTH RESPONSE 3 AND BRAIN-DERIVED NEUROTROPHIC FACTOR IN BIPOLAR DISORDER}

This perspective article presents an accumulation of findings indicating that changes in BDNF are a consistent feature of BD, and may contribute to the pathophysiology of this mental illness. Here we summarize the potential molecular links between BDNF and the IEG transcription factor EGR3, two molecules that may each play a critical role in the impaired cellular resilience related to BD (Manji et al., 2003; Berk et al., 2011; Pfaffenseller et al., 2016).

As we have discussed, BDNF is reported to be altered in $\mathrm{BD}$ in both peripheral and central tissue, and it is possible that blood BDNF levels correlate positively with brain BDNF levels (Klein et al., 2011). Thus, presuming that the reduced peripheral BDNF levels observed in BD patients accurately reflect levels in the brain, and considering that BDNF may induce EGR3 expression via PKC/MAPK dependent pathway (Roberts et al., 2006), the decreased levels of BDNF may account, at least in part, for the prefrontal cortex EGR3 repression that we identified in $\mathrm{BD}$ (Pfaffenseller et al., 2016).

Alternatively, or in addition, EGR3 may indirectly induce BDNF expression via regulation of NMDAR. In mice, EGR3 has been shown to be required for the function of NR2B-containing NMDARs (Gallitano-Mendel et al., 2007). A study has shown that the majority of NMDAR protein levels (NR1 subunits) in rat cortical neurons are regulated by the transcription factors CREB 
and EGR3 (Kim et al., 2012), and NMDAR activation stimulates BDNF synthesis (Marini et al., 1998). It is noteworthy that NMDARs have a critical role for memory processes involving long-term potentiation (LTP) and long-term depression (LTD; Bliss and Collingridge, 1993; Collingridge and Bliss, 1995), and it has been demonstrated that BDNF as well as EGR3 participates in LTP and LTD processes. For example, the administration of exogenous BDNF to mice deficient for BDNF restores the impairment in LTP (Patterson et al., 2001). Mice deficient for EGR3 have deficits in hippocampal LTD and exhibit dysfunction in NMDAR subclasses (NR1/NR2B; Gallitano-Mendel et al., 2007). Thus, dysfunction in signaling pathways involving both BDNF and EGR3 may underlie the cognitive impairment shown by $\mathrm{BD}$ patients.

In addition, EGR3 also regulates the expression of NGFR ( $p 75$ NTR, Gao et al., 2007), a receptor for neurotrophins involved in the control of axonal elongation, neuron survival and differentiation (Dechant and Barde, 2002). Neurogenic potential seems to be mediated by $\mathrm{p} 75$ (NTR) and is greatly enhanced in vitro after treatment with BDNF (Young et al., 2007), indicating this EGR3-regulated mechanism integrate a relevant pathway involved in neuroplasticity that likely correspond to changes in BDNF levels in psychiatric conditions.

Taking this into account, we also suggest that EGR3 repression seen in $\mathrm{BD}$ patients could be responsible for the reduced BDNF levels associated to this illness. It is most likely to think in a feedback network than in a cause-and-effect relationship considering that EGR3 is responsive to BDNF and regulates NMDAR, which transcription is also mediated by BDNF through activation of the TrKB receptor and in turn induce BDNF synthesis (Kim et al., 2012). Thus, we propose a feed-forward regulatory gene network involving EGR3 and BDNF (Figure 1) that may regulate biological mechanisms to change neuronal expression according to endogenous or environmental stimuli, and this process might potentially be related to $\mathrm{BD}$ pathophysiology.

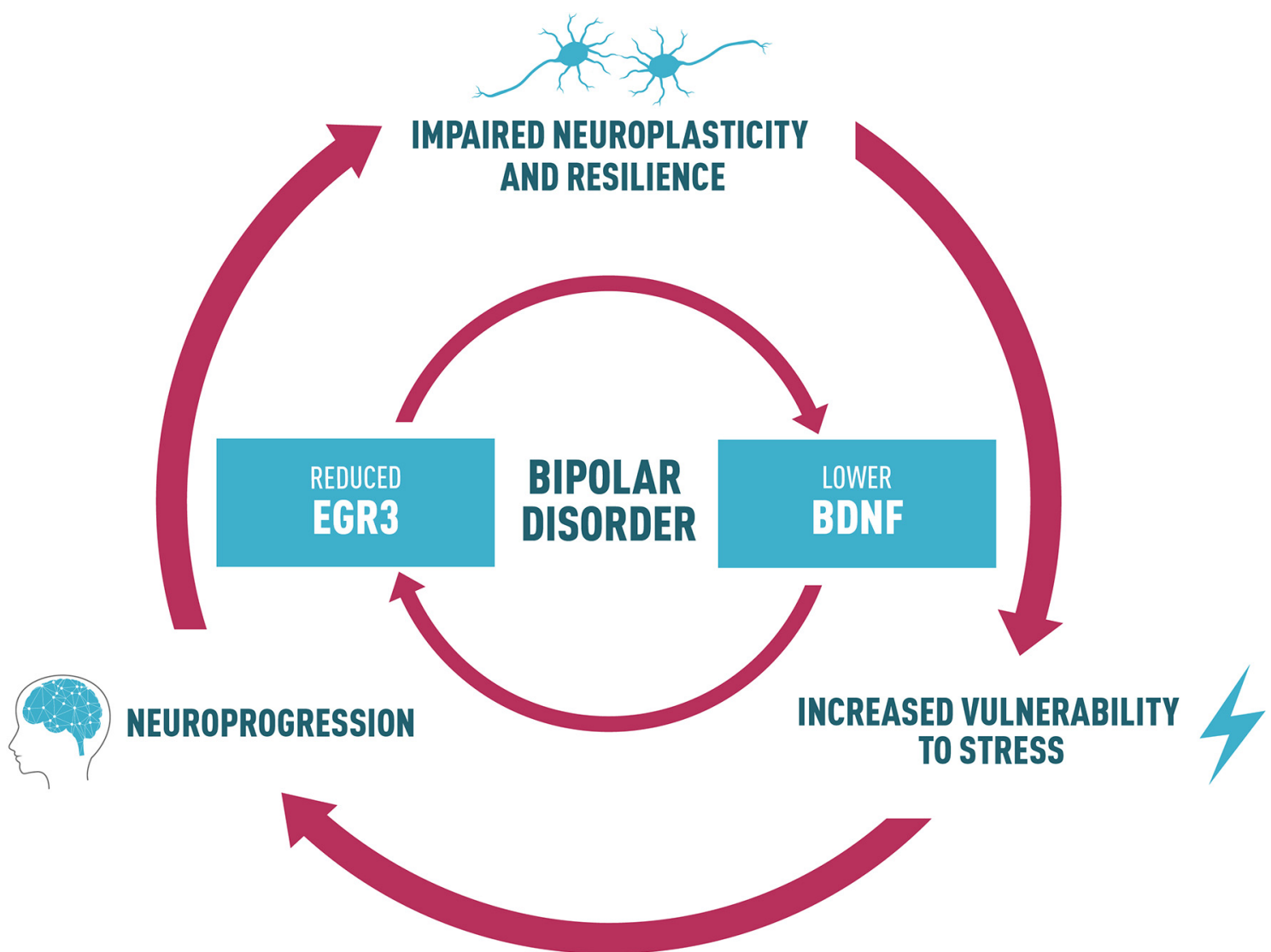

FIGURE 2 | Proposed link between BDNF and EGR3 and their potential role in BD. Lower BDNF levels observed in BD patients may influence the reduced EGR3 levels seen in BD since BDNF regulates EGR3. EGR3 may also indirectly induce BDNF expression via regulation of NMDAR. Thus, we also suggest that reduced EGR3 expression, as we have seen in BD patients in our study, could contribute to lower BDNF levels associated with this illness. Based on these findings, we propose a feedback-loop reinforcing this dysfunctional pathway that could, in turn, impair neuroplasticity and resilience. This process may ultimately lead to increased vulnerability to stress, and could result in alterations in several biological factors that contribute to BD, such as abnormal structural brain changes and the associated cognitive and functional decline (a process called neuroprogression). The neural circuits additionally disrupted in this process could contribute to an impaired neuroplasticity and resilience, increasing vulnerability to stress and mood episodes and reduced responsiveness to pharmacotherapy, thus perpetuating a vicious cycle in illness progression. 
Altogether, the findings discussed in this article suggest a potential regulatory pathway that possibly is disrupted in $\mathrm{BD}$. For many years, evidence has pointed to alterations in neurotrophic factors in BD suggesting these changes could contribute to an impaired neuroplasticity and resilience. However, the mechanisms underlying this impairment remain unknown. The identified network focused on EGR3 thus emerges as a potential central player responsible for some of changes observed in BD such as a reduced neurotrophic support. Taking into consideration that EGR3 translates environmental events into neural long-term alterations, the possible disturbance in molecular pathways involving EGR3 could result in an impaired response and adaptation to stress.

We suggest experimental approaches to test the hypothesis regarding a potential feed-forward mechanism involving BDNF and EGR3 and its role in $\mathrm{BD}$, which might contribute to understanding its pathophysiology. Moreover, as a central transcription factor of a gene network that regulates crucial neurobiological processes, EGR3 may be a promising pharmacological target. Modulation of IEGs as EGR3 might be beneficial since they could provide a dynamic and fast response to neural activity and thus a sustained adaptation through regulation of an entire regulatory gene network.

With this perspective, we propose that a reduction in EGR3 in BD could contribute to alterations in a neurotrophin cascade in this disorder, which includes reduced BDNF levels. A feedback-loop reinforcing this dysfunctional

\section{REFERENCES}

Aldinger, F., and Schulze, T. G. (2017). Environmental factors, life events, and trauma in the course of bipolar disorder. Psychiatry Clin. Neurosci. 71, 6-17. doi: $10.1111 /$ pcn. 12433

Beckmann, A. M., and Wilce, P. A. (1997). Egr transcription factors in the nervous system. Neurochem. Int. 31, 477-510. doi: 10.1016/s0197-0186(96)00136-2

Berk, M. (2009). Neuroprogression: pathways to progressive brain changes in bipolar disorder. Int. J. Neuropsychopharmacol. 12, 441-445. doi: 10.1017/S1461145708009498

Berk, M., Kapczinski, F., Andreazza, A. C., Dean, O. M., Giorlando, F., Maes, M., et al. (2011). Pathways underlying neuroprogression in bipolar disorder: focus on inflammation, oxidative stress and neurotrophic factors. Neurosci. Biobehav. Rev. 35, 804-817. doi: 10.1016/j.neubiorev.2010.10.001

Bliss, T. V., and Collingridge, G. L. (1993). A synaptic model of memory: long-term potentiation in the hippocampus. Nature 361, 31-39. doi: 10.1038/ 361031a0

Bortolato, B., Miskowiak, K. W., Köhler, C. A., Vieta, E., and Carvalho, A. F. (2015). Cognitive dysfunction in bipolar disorder and schizophrenia: a systematic review of meta-analyses. Neuropsychiatr. Dis. Treat. 11, 3111-3125. doi: 10.2147/NDT.S76700

Bourne, C., Aydemir, Ö., Balanzá-Martánez, V., Bora, E., Brissos, S., Cavanagh, J. T., et al. (2013). Neuropsychological testing of cognitive impairment in euthymic bipolar disorder: an individual patient data metaanalysis. Acta Psychiatr. Scand. 128, 149-162. doi: 10.1111/acps.12133

Champagne, F. A., and Curley, J. P. (2009). Epigenetic mechanisms mediating the long-term effects of maternal care on development. Neurosci. Biobehav. Rev. 33, 593-600. doi: 10.1016/j.neubiorev.2007.10.009

Collingridge, G. L., and Bliss, T. V. (1995). Memories of NMDA receptors and LTP. Trends Neurosci. 18, 54-56. doi: 10.1016/0166-2236(95) 93868-x

Craddock, N., and Sklar, P. (2013). Genetics of bipolar disorder. Lancet 381, 1654-1662. doi: 10.1016/S0140-6736(13)60855-7 pathway could, in turn, impair neuroplasticity and resilience (Figure 2). This process may ultimately lead to increased vulnerability to stress, underlying the risk to develop the symptoms and $\mathrm{BD}$ neuroprogression. Thus, we suggest an interesting link between EGR3 and BDNF in BD, and this shared biological pathway could provide potential targets for follow-up studies to clarify mechanisms responsible for the interaction between environment and genetic factors that influence $\mathrm{BD}$ and for the development of novel therapeutics.

\section{AUTHOR CONTRIBUTIONS}

All authors provided substantial contributions to the work. BP, FKa and FKl participated in the article design and outline. $\mathrm{BP}$ wrote the first draft. ALG revised it critically for relevant scientific content. After a few revisions and editing by all authors, the article was submitted.

\section{ACKNOWLEDGMENTS}

This study was supported by the Brazilian funds MCTI/CNPq INCT-TM/CAPES/FAPESP (465458/2014-9), CNPq/MS/DECIT (466989/2014-8) and PRONEX/FAPERGS (16/2551-0000499-4), and also by the grant NIH R01 MH097803 to ALG, without interference in the ongoing work. We are grateful to Cezar Farias for figures processing and editing.

Cunha, A. B., Frey, B. N., Andreazza, A. C., Goi, J. D., Rosa, A. R., Gonçalves, C. A., et al. (2006). Serum brain-derived neurotrophic factor is decreased in bipolar disorder during depressive and manic episodes. Neurosci. Lett. 398, 215-219. doi: 10.1016/j.neulet.2005.12.085

Dechant, G., and Barde, Y. A. (2002). The neurotrophin receptor p75(NTR): novel functions and implications for diseases of the nervous system. Nat. Neurosci. 5, 1131-1136. doi: 10.1038/nn1102-1131

Eldredge, L. C., Gao, X. M., Quach, D. H., Li, L., Han, X., Lomasney, J., et al. (2008). Abnormal sympathetic nervous system development and physiological dysautonomia in Egr3-deficient mice. Development 135, 2949-2957. doi: 10.1242/dev.023960

Fernandes, B. S., Berk, M., Turck, C. W., Steiner, J., and Gonçalves, C. A. (2014). Decreased peripheral brain-derived neurotrophic factor levels are a biomarker of disease activity in major psychiatric disorders: a comparative meta-analysis. Mol. Psychiatry 19, 750-751. doi: 10.1038/mp.2013.172

Fernandes, B. S., Gama, C. S., Ceresér, K. M., Yatham, L. N., Fries, G. R., Colpo, G. et al. (2011). Brain-derived neurotrophic factor as a state-marker of mood episodes in bipolar disorders: a systematic review and meta-regression analysis. J. Psychiatr. Res. 45, 995-1004. doi: 10.1016/j.jpsychires.2011.03.002

Fornito, A., Malhi, G. S., Lagopoulos, J., Ivanovski, B., Wood, S. J., Velakoulis, D., et al. (2007). In vivo evidence for early neurodevelopmental anomaly of the anterior cingulate cortex in bipolar disorder. Acta Psychiatr. Scand. 116, 467-472. doi: 10.1111/j.1600-0447.2007.01069.x

Francis, T. C., Chandra, R., Gaynor, A., Konkalmatt, P., Metzbower, S. R., Evans, B., et al. (2017). Molecular basis of dendritic atrophy and activity in stress susceptibility. Mol. Psychiatry 22, 1512-1519. doi: 10.1038/mp.2017.178

Frey, B. N., Andreazza, A. C., Houenou, J., Jamain, S., Goldstein, B. I., Frye, M. A., et al. (2013). Biomarkers in bipolar disorder: a positional paper from the international society for bipolar disorders biomarkers task force. Aust. N Z J. Psychiatry 47, 321-332. doi: 10.1177/0004867413478217

Fries, G. R., Pfaffenseller, B., Stertz, L., Paz, A. V., Dargél, A. A., Kunz, M., et al. (2012). Staging and neuroprogression in bipolar disorder. Curr. Psychiatry Rep. 14, 667-675. doi: 10.1007/s11920-012-0319-2 
Fujimura, H., Altar, C. A., Chen, R., Nakamura, T., Nakahashi, T., Kambayashi, J., et al. (2002). Brain-derived neurotrophic factor is stored in human platelets and released by agonist stimulation. Thromb. Haemost. 87, 728-734.

Gallitano, A. L., Tillman, R., Dinu, V., and Geller, B. (2012). Family-based association study of early growth response gene 3 with child bipolar I disorder. J. Affect. Disord. 138, 387-396. doi: 10.1016/j.jad.2012.01.011

Gallitano-Mendel, A., Izumi, Y., Tokuda, K., Zorumski, C. F., Howell, M. P., Muglia, L. J., et al. (2007). The immediate early gene early growth response gene 3 mediates adaptation to stress and novelty. Neuroscience 148, 633-643. doi: 10.1016/j.neuroscience.2007.05.050

Gallitano-Mendel, A., Wozniak, D. F., Pehek, E. A., and Milbrandt, J. (2008). Mice lacking the immediate early gene Egr3 respond to the anti-aggressive effects of clozapine yet are relatively resistant to its sedating effects. Neuropsychopharmacology 33, 1266-1275. doi: 10.1038/sj.npp.1301505

Gao, X., Daugherty, R. L., and Tourtellotte, W. G. (2007). Regulation of low affinity neurotrophin receptor $\left(\mathrm{p} 75^{N T R}\right)$ by early growth response (Egr) transcriptional regulators. Mol. Cell. Neurosci. 36, 501-514. doi: 10.1016/j.mcn.2007.08.013

Grande, I., Fries, G. R., Kunz, M., and Kapczinski, F. (2010). The role of BDNF as a mediator of neuroplasticity in bipolar disorder. Psychiatry Investig. 7, 243-250. doi: 10.4306/pi.2010.7.4.243

Guo, A. Y., Sun, J., Jia, P., and Zhao, Z. (2010). A novel microRNA and transcription factor mediated regulatory network in schizophrenia. BMC Syst. Biol. 4:10. doi: 10.1186/1752-0509-4-10

Hanson, D. R., and Gottesman, I. I. (2005). Theories of schizophrenia: a geneticinflammatory-vascular synthesis. BMC Med. Genet. 6:7. doi: 10.1186/14712350-6-7

Hippenmeyer, S., Shneider, N. A., Birchmeier, C., Burden, S. J., Jessell, T. M., and Arber, S. (2002). A role for neuregulin1 signaling in muscle spindle differentiation. Neuron 36, 1035-1049. doi: 10.1016/s0896-6273(02)01101-7

Honkaniemi, J., Zhang, J. S., Longo, F. M., and Sharp, F. R. (2000). Stress induces zinc finger immediate early genes in the rat adrenal gland. Brain Res. 877, 203-208. doi: 10.1016/s0006-8993(00)02673-1

Huentelman, M. J., Muppana, L., Corneveaux, J. J., Dinu, V., Pruzin, J. J., Reiman, R., et al. (2015). Association of SNPs in EGR3 and ARC with schizophrenia supports a biological pathway for schizophrenia risk. PLoS One 10:e0135076. doi: 10.1371/journal.pone.0135076

Jansen, K., Cardoso, T. A., Fries, G. R., Branco, J. C., Silva, R. A., KauerSant'Anna, M., et al. (2016). Childhood trauma, family history, and their association with mood disorders in early adulthood. Acta Psychiatr. Scand. 134, 281-286. doi: 10.1111/acps.12551

Kapczinski, F., Vieta, E., Andreazza, A. C., Frey, B. N., Gomes, F. A., Tramontina, J., et al. (2008). Allostatic load in bipolar disorder: implications for pathophysiology and treatment. Neurosci. Biobehav. Rev. 32, 675-692. doi: 10.1016/j.neubiorev.2007.10.005

Kauer-Sant'Anna, M., Kapczinski, F., Andreazza, A. C., Bond, D. J., Lam, R. W., Young, L. T., et al. (2009). Brain-derived neurotrophic factor and inflammatory markers in patients with early- vs. late-stage bipolar disorder. Int. J. Neuropsychopharmacol. 12, 447-458. doi: 10.1017/s1461145708009310

Kieseppa, T., Partonen, T., Haukka, J., Kaprio, J., and Lönnqvist, J. (2004). High concordance of bipolar I disorder in a nationwide sample of twins. Am. J. Psychiatry 161, 1814-1821. doi: 10.1176/appi.ajp.161.10.1814

Kim, H. W., Rapoport, S. I., and Rao, J. S. (2010). Altered expression of apoptotic factors and synaptic markers in postmortem brain from bipolar disorder patients. Neurobiol. Dis. 37, 596-603. doi: 10.1016/j.nbd.2009.11.010

Kim, J. H., Roberts, D. S., Hu, Y., Lau, G. C., Brooks-Kayal, A. R., Farb, D. H., et al. (2012). Brain-derived neurotrophic factor uses CREB and Egr3 to regulate NMDA receptor levels in cortical neurons. J. Neurochem. 120, 210-219. doi: 10.1111/j.1471-4159.2011.07555.x

Kim, S. H., Song, J. Y., Joo, E. J., Lee, K. Y., Ahn, Y. M., and Kim, Y. S. (2010). EGR3 as a potential susceptibility gene for schizophrenia in Korea. Am. J. Med. Genet. B Neuropsychiatr. Genet. 153B, 1355-1360. doi: 10.1002/ajmg.b. 31115

Klein, A. B., Williamson, R., Santini, M. A., Clemmensen, C., Ettrup, A., Rios, M., et al. (2011). Blood BDNF concentrations reflect brain-tissue BDNF levels across species. Int. J. Neuropsychopharmacol. 14, 347-353. doi: $10.1017 /$ S1461145710000738

Knable, M. B., Barci, B. M., Webster, M. J., Meador-Woodruff, J., and Torrey, E. F. (2004). Stanley Neuropathology Consortium. Molecular abnormalities of the hippocampus in severe psychiatric illness: postmortem findings from the Stanley Neuropathology Consortium. Mol. Psychiatry 9, 609-620, 544. doi: 10.1038/sj.mp.4001471

Li, L., Carter, J., Gao, X., Whitehead, J., and Tourtellotte, W. G. (2005). The neuroplasticity-associated arc gene is a direct transcriptional target of early growth response (Egr) transcription factors. Mol. Cell. Biol. 25, 10286-10300. doi: $10.1128 / \mathrm{mcb} .25 .23 .10286-10300.2005$

Li, L., Yun, S. H., Keblesh, J., Trommer, B. L., Xiong, H., Radulovic, J., et al. (2007). Egr3, a synaptic activity regulated transcription factor that is essential for learning and memory. Mol. Cell. Neurosci. 35, 76-88. doi: 10.1016/j.mcn. 2007.02.004

Lin, P. Y. (2009). State-dependent decrease in levels of brain-derived neurotrophic factor in bipolar disorder: a meta-analytic study. Neurosci. Lett. 466, 139-143. doi: 10.1016/j.neulet.2009.09.044

Lu, B., Nagappan, G., and Lu, Y. (2014). BDNF and synaptic plasticity, cognitive function, and dysfunction. Handb. Exp. Pharmacol. 220, 223-250. doi: 10.1007/978-3-642-45106-5_9

Lu, B., Pang, P. T., and Woo, N. H. (2005). The yin and yang of neurotrophin action. Nat. Rev. Neurosci. 6, 603-614. doi: 10.1038/nrn1726

Manji, H. K., Quiroz, J. A., Payne, J. L., Singh, J., Lopes, B. P., Viegas, J. S., et al. (2003). The underlying neurobiology of bipolar disorder. World Psychiatry 2, 136-146.

Mansour, H. A., Talkowski, M. E., Wood, J., Chowdari, K. V., McClain, L., Prasad, K., et al. (2009). Association study of 21 circadian genes with bipolar I disorder, schizoaffective disorder, and schizophrenia. Bipolar Disord. 11, 701-710. doi: 10.1111/j.1399-5618.2009.00756.x

Maple, A. M., Zhao, X., Elizalde, D. I., McBride, A. K., and Gallitano, A. L. (2015). Htr2a expression responds rapidly to environmental stimuli in an Egr3-Dependent manner. ACS Chem. Neurosci. 6, 1137-1142. doi: 10.1021/ acschemneuro.5b00031

Marini, A. M., Rabin, S. J., Lipsky, R. H., and Mocchetti, I. (1998). Activity-dependent release of brain-derived neurotrophic factor underlies the neuroprotective effect of N-methyl-D-aspartate. J. Biol. Chem. 273, 29394-29399. doi: 10.1074/jbc.273.45.29394

Merikangas, K. R., Jin, R., He, J. P., Kessler, R. C., Lee, S., Sampson, N. A., et al. (2011). Prevalence and correlates of bipolar spectrum disorder in the world mental health survey initiative. Arch. Gen. Psychiatry 68, 241-251. doi: 10.1001/archgenpsychiatry.2011.12

Mexal, S., Frank, M., Berger, R., Adams, C. E., Ross, R. G., Freedman, R., et al. (2005). Differential modulation of gene expression in the NMDA postsynaptic density of schizophrenic and control smokers. Mol. Brain Res. 139, 317-332. doi: 10.1016/j.molbrainres.2005.06.006

Minichiello, L. (2009). TrkB signalling pathways in LTP and learning. Nat. Rev. Neurosci. 10, 850-860. doi: 10.1038/nrn2738

Moises, H. W., Zoega, T., and Gottesman, I. (2002). The glial growth factors deficiency and synaptic destabilization hypothesis of schizophrenia. BMC Psychiatry 2:8. doi: 10.1186/1471-244x-2-8

Munkholm, K., Vinberg, M., and Kessing, L. V. (2015). Peripheral blood brainderived neurotrophic factor in bipolar disorder: a comprehensive systematic review and meta-analysis. Mol. Psychiatry 21, 216-228. doi: 10.1038/mp. 2015.54

Neves-Pereira, M., Cheung, J. K., Pasdar, A., Zhang, F., Breen, G., Yates, P., et al. (2005). BDNF gene is a risk factor for schizophrenia in a Scottish population. Mol. Psychiatry 10, 208-212. doi: 10.1038/sj.mp.4001575

O’Donovan, K. J., Tourtellotte, W. G., Millbrandt, J., and Baraban, J. M. (1999). The EGR family of transcription regulatory factors: progress at the interface of molecular and systems neuroscience. Trends Neurosci. 22, 167-173. doi: 10.1016/s0166-2236(98)01343-5

Park, H., and Poo, M. M. (2013). Neurotrophin regulation of neural circuit development and function. Nat. Rev. Neurosci. 14, 7-23. doi: 10.1038/nrn3379

Patterson, S. L., Pittenger, C., Morozov, A., Martin, K. C., Scanlin, H., Drake, C., et al. (2001). Some forms of cAMP-mediated long-lasting potentiation are associated with release of BDNF and nuclear translocation of phosphoMAP kinase. Neuron 32, 123-140. doi: 10.1016/S0896-6273(01) 00443-3

Pérez-Cadahía, B., Drobic, B., and Davie, J. R. (2011). Activation and function of immediate-early genes in the nervous system. Biochem. Cell Biol. 89, 61-73. doi: $10.1139 / 010-138$ 
Pfaffenseller, B., da Silva Magalhães, P. V., De Bastiani, M. A., Castro, M. A., Gallitano, A. L., Kapczinski, F., et al. (2016). Differential expression of transcriptional regulatory units in the prefrontal cortex of patients with bipolar disorder: potential role of early growth response gene 3. Transl. Psychiatry 6:e805. doi: 10.1038/tp.2016.78

Poirier, R., Cheval, H., Mailhes, C., Garel, S., Charnay, P., Davis, S., et al. (2008). Distinct functions of egr gene family members in cognitive processes. Front. Neurosci. 2, 47-55. doi: 10.3389/neuro.01.002.2008

Post, R. M. (2007). Role of BDNF in bipolar and unipolar disorder: clinical and theoretical implications. J. Psychiatr. Res. 41, 979-990. doi: 10.1016/j.jpsychires. 2006.09.009

Quach, D. H., Oliveira-Fernandes, M., Gruner, K. A., and Tourtellotte, W. G. (2013). A sympathetic neuron autonomous role for Egr3-mediated gene regulation in dendrite morphogenesis and target tissue innervation. J. Neurosci. 33, 4570-4583. doi: 10.1523/jneurosci.5481-12.2013

Ray, M. T., Shannon Weickert, C., and Webster, M. J. (2014). Decreased BDNF and TrkB mRNA expression in multiple cortical areas of patients with schizophrenia and mood disorders. Transl. Psychiatry 4:e389. doi: 10.1038/tp. 2014.26

Reinhart, V., Bove, S. E., Volfson, D., Lewis, D. A., Kleiman, R. J., and Lanz, T. A. (2015). Evaluation of TrkB and BDNF transcripts in prefrontal cortex, hippocampus and striatum from subjects with schizophrenia, bipolar disorder and major depressive disorder. Neurobiol. Dis. 77, 220-227. doi: 10.1016/j.nbd. 2015.03.011

Roberts, D. S., Hu, Y., Lund, I. V., Brooks-Kayal, A. R., and Russek, S. J. (2006). Brain-derived neurotrophic factor (BDNF)-induced synthesis of early growth response factor 3 (Egr3) controls the levels of type A GABA receptor a 4 subunits in hippocampal neurons. J. Biol. Chem. 281, 29431-29435. doi: 10.1074/jbc.c600167200

Robinson, L. J., Thompson, J. M., Gallagher, P., Goswami, U., Young, A. H., Ferrier, I. N., et al. (2006). A meta-analysis of cognitive deficits in euthymic patients with bipolar disorder. J. Affect. Disord. 93, 105-115. doi: 10.1016/j.jad. 2006.02.016

Schmitt, A., Malchow, B., Hasan, A., and Falkai, P. (2014). The impact of environmental factors in severe psychiatric disorders. Front. Neurosci. 8:19. doi: 10.3389/fnins.2014.00019

Senba, E., and Ueyama, T. (1997). Stress-induced expression of immediate early genes in the brain and peripheral organs of the rat. Neurosci. Res. 29, 183-207. doi: 10.1016/s0168-0102(97)00095-3

Sklar, P., Gabriel, S. B., McInnis, M. G., Bennett, P., Lim, Y.-M., Tsan, G., et al. (2002). Family-based association study of 76 candidate genes in bipolar disorder: BDNF is a potential risk locus. Brain-derived neutrophic factor. Mol. Psychiatry 7, 579-593. doi: 10.1038/sj.mp.4001058

Strakowski, S. M., Delbello, M. P., and Adler, C. M. (2005). The functional neuroanatomy of bipolar disorder: a review of neuroimaging findings. Mol. Psychiatry 10, 105-116. doi: 10.1038/sj.mp. 4001585

Strakowski, S. M., DelBello, M. P., Zimmerman, M. E., Getz, G. E., Mills, N. P., Ret, J., et al. (2002). Ventricular and periventricular structural volumes in firstversus multiple-episode bipolar disorder. Am. J. Psychiatry 159, 1841-1847. doi: 10.1176/appi.ajp.159.11.1841
Thompson Ray, M., Weickert, C. S., Wyatt, E., and Webster, M. J. (2011). Decreased BDNF, trkB-TK+ and GAD67 mRNA expression in the hippocampus of individuals with schizophrenia and mood disorders. J. Psychiatry Neurosci. 36, 195-203. doi: 10.1503/jpn.100048

Thompson, C. L., Wisor, J. P., Lee, C. K., Pathak, S. D., Gerashchenko, D., Smith, K. A., et al. (2010). Molecular and anatomical signatures of sleep deprivation in the mouse brain. Front. Neurosci. 4:165. doi: 10.3389/fnins.2010. 00165

Tourtellotte, W. G., and Milbrandt, J. (1998). Sensory ataxia and muscle spindle agenesis in mice lacking the transcription factor Egr3. Nat. Genet. 20, 87-91. doi: $10.1038 / 1757$

Tseng, M., Alda, M., Xu, L., Sun, X., Wang, J. F., Grof, P., et al. (2008). BDNF protein levels are decreased in transformed lymphoblasts from lithiumresponsive patients with bipolar disorder. J. Psychiatry Neurosci. 33, 449-453.

Weigelt, K., Carvalho, L. A., Drexhage, R. C., Wijkhuijs, A., de Wit, H., van Beveren, N. J., et al. (2011). TREM-1 and DAP12 expression in monocytes of patients with severe psychiatric disorders. EGR3, ATF3 and PU.1 as important transcription factors. Brain Behav. Immun. 25, 1162-1169. doi: 10.1016/j.bbi. 2011.03.006

Williams, A. A., Ingram, W. M., Levine, S., Resnik, J., Kamel, C. M., Lish, J. R., et al. (2012). Reduced levels of serotonin 2A receptors underlie resistance of Egr3-deficient mice to locomotor suppression by clozapine. Neuropsychopharmacology 37, 2285-2298. doi: 10.1038/npp.2012.81

Yamada, K., Gerber, D. J., Iwayama, Y., Ohnishi, T., Ohba, H., Toyota, T., et al. (2007). Genetic analysis of the calcineurin pathway identifies members of the EGR gene family, specifically EGR3, as potential susceptibility candidates in schizophrenia. Proc. Natl. Acad. Sci. U S A 104, 2815-2820. doi: 10.1073/pnas. 0610765104

Yamagata, K., Kaufmann, W. E., Lanahan, A., Papapavlou, M., Barnes, C. A., Andreasson, K. I., et al. (1994). Egr3/Pilot, a zinc finger transcription factor, is rapidly regulated by activity in brain neurons and colocalizes with Egr1/zif268. Learn. Mem. 1, 140-152.

Young, K. M., Merson, T. D., Sotthibundhu, A., Coulson, E. J., and Bartlett, P. F. (2007). p75 neurotrophin receptor expression defines a population of BDNF-responsive neurogenic precursor cells. J. Neurosci. 27, 5146-5155. doi: 10.1523/JNEUROSCI.0654-07.2007

Zhang, R., Lu, S., Meng, L., Min, Z., Tian, J., Valenzuela, R. K., et al. (2012). Genetic evidence for the association between the early growth response 3 (EGR3) gene and schizophrenia. PLoS One 7:e30237. doi: 10.1371/journal.pone.0030237

Conflict of Interest Statement: The authors declare that the research was conducted in the absence of any commercial or financial relationships that could be construed as a potential conflict of interest.

Copyright (C) 2018 Pfaffenseller, Kapczinski, Gallitano and Klamt. This is an open-access article distributed under the terms of the Creative Commons Attribution License (CC BY). The use, distribution or reproduction in other forums is permitted, provided the original author(s) and the copyright owner are credited and that the original publication in this journal is cited, in accordance with accepted academic practice. No use, distribution or reproduction is permitted which does not comply with these terms. 